\title{
Implicit word activation during prerecognition processing: False recognition and remember/know judgments
}

\author{
WILLIAM P. WALLACE, CHRISTINE P. MALONE, and ALISON D. SPOO \\ University of Nevada, Reno, Nevada
}

\begin{abstract}
Recognition memory for spoken words is influenced by phonetic resemblance between test words and items presented during study. Presentation of derived nonwords (e.g., /d/ransparent or transparen $/ \mathrm{d} /$ ) on a study list produces a higher than normal false recognition rate to base words (e.g., transparent). Test words that share beginning phonemes with studied nonwords have more false recognitions than do those that share ending phonemes. The latter difference has been attributed to familiarity resulting from prerecognition processing of spoken stimuli. As a listener hears /træns/, "transparent" may be activated as a potential solution. In the present experiments, we minimized contributions of postrecognition processing to this phenomenon by presenting a semantically unrelated test word (transportation) that was also expected to be activated during prerecognition stages of processing. The results indicated that false recognition was increased for words presumed to be activated only during prerecognition processing. Remember $(\mathrm{R})$ and know (K) judgments revealed that the majority of studied words were $\mathrm{R}$, and the majority of false recognitions were $\mathrm{K}$. The lowest proportion of $R$ judgments occurred for test words that were not activated during postrecognition processing (e.g., transportation and control words).
\end{abstract}

Cognitive processing activities engaged by one task may affect performance on other tasks. In spoken-word recognition, words that are consistent with sensory information represent potential lexical solutions and are activated implicitly. The activation process may produce subtle influences on a participant's performance on a recognition memory test. Familiarity has figured prominently as a source of confusion in recognition memory, and the implicit generation of new test words during srudy increases difficulty in discriminating than from old test words (e.g., Underwood, 1965, 1983).

For adults, false recognitions occur frequently to distractors that are related to studied words (see, e.g., Roediger \& McDermott, 1995; Underwood, 1965). The theoretical focus has generally been placed on postrecognition processing activities during study trial presentations that are triggered once a word has been recognized (e.g., rabbit activates animal after/ræbit/ has been identified). Prerecognition processing involved in arriving at a recognition decision for spoken words during study trials is often neglected in interpretations of memory phenomena. However, if it is assumed that words activated in the course of the perceiving of spoken words acquire familiarity just as they do when activated subsequently to recognition, then prerecognition word activation ought to have predictable

Portions of this paper were prepared while the first author was a Visiting Fellow at the University of New South Wales, and the support that the School of Psychology provided is gratefully acknowledged. Reprint requests may be sent to W. P. Wallace, Department of Psychology, University of Nevada, Reno, NV 89557 (e-mail: wallace@unr.edu). effects on memory. Durations for prerecognition activation normally entail only a few hundred milliseconds, but in typical list-learning paradigms these durations may not be trivial. If an item requires $750 \mathrm{msec}$ for identification, and if successive items occur every $3 \mathrm{sec}$, then a nontrivial $25 \%$ of the study time dedicated to the item involves prerecognition processing.

Mistaking a new word on a recognition memory test as one that has been presented during study is more likely to occur if the new word resembles one or more study items. Such demonstrations usually involve semantic resemblance. However, similar effects have occurred with phonetic resemblance (see, e.g., Nelson \& Davis, 1972; Sommers \& Lewis, 1999; Wallace, 1968). Potential solution words for spoken items may be activated implicitly as a spoken stimulus progresses over time (see Bard, 1990; Marslen-Wilson, 1987; McClelland \& Elman, 1986; Norris, 1994; Vroomen \& de Gelder, 1997). The activation process results in increments of familiarity for activated words. If a new word on a recognition memory test seems familiar, the listener may become confused and may incorrectly attribute the familiarity source to actual study presentations. In a "derived-nonword" variation on the recognition memory paradigm, participants listened to a study list of words and nonwords. Nonwords were derived from new test words by changing a single phoneme. False recognitions to test words were increased if their derived nonwords were presented during study, and they were higher when the critical phoneme change occurred late in the nonword (Wallace, Stewart, Shaffer, \& Wilson, 1998; Wallace, Stewart, Sherman, \& Mellor, 1995). 
A "derived-word" version of this paradigm can approximate the phonemic similarity conditions that are created with derived nonwords (transparent or vegetation as derived words for transportation). Although this variation does not provide comparable levels of control that are possible with derived nonwords, it provides one notable advantage. After transparent or vegetation is recognized, implicit postrecognition word activation should proceed along semantic lines (word association data indicate that phonetically similar association responses are infrequent; see Postman \& Keppel, 1970). The derivedword procedure does not eliminate postrecognition word activation. However, it should direct postrecognition processing away from activation of the critical test word. Wallace, Stewart, and Malone (1995) demonstrated that false recognitions of a new test word, such as transportation, were more frequent when the study list had a critical word with early overlapping phonemes (transparent) as opposed to late overlapping phonemes (vegetation).

The present experiments involved the derived-nonword paradigm. We were concerned with prerecognition word activation. Postrecognition activation of critical test words was minimized by using test words that were phonetically related (PR) to the base words from which study nonwords were derived. The usual procedure has involved a recognition memory test for a word such as transparent, following study of either its early change derived nonword, /d/ransparent, or its late change derived nonword, transparen $/ \mathrm{d} /$. A corresponding PR test word, transportation, has initial phonemes in common with the original test word and should be activated during the initial stages of prerecognition processing. However, neither a recognized derived nonword nor an elicited base word should be an effective postrecognition retrieval cue for a PR test word. Wallace, Stewart, and Malone (1995) provided confirmation for this argument in the derivedword paradigm. The derived-nonword paradigm enjoys a number of methodological benefits in comparison with the derived-word paradigm, particularly in terms of more precise control over the nature, location, and number of shared phonemes between respective study and test items. Thus, it was important to demonstrate that prerecognition processes contribute to the false recognition phenomena with this paradigm.

\section{EXPERIMENT 1}

\begin{abstract}
Method
Design. Three variables were combined factorially in a mixed design. The between-subjects variable involved the relationship between new words on a recognition memory test and nonword study items that they resembled. For the base word test group (BW), some new words on the test differed from studied nonwords by a single phoneme, and for the phonetically related group (PR), each BW test word was replaced with a word that shared initial phonemes with it. For Group PR, test words for late change derived nonwords were assumed to be activated only during the prerecognition processing stage, so the PR code might also serve as a reminder for "prere-
\end{abstract}

cognition" activation. The BW condition would likely reflect the influence of both prerecognition and postrecognition activation. The remaining two variables were manipulated within groups. The variable of primary interest was location of a substituted phoneme for BW test words: When it appeared late (L), corresponding nonwords and new test words had overlapping phonemes in beginning positions, and when it appeared early (E), corresponding nonwords and new test words had overlapping phonemes in ending positions. Note that the $\mathrm{L}$ relationship was maintained for PR test words, whereas the E relationship held only for BW (transparen/d/ has initial phonemes in common with the PR test word transportation, but $/ \mathrm{d} /$ ransparent does not have final phonemes in common with transportation). A repetition variable was included so that there would be "strength" differences among items presented on the study trial. Half of the critical items were presented once during study, and half were presented three times.

Materials. Lists were constructed from 48 sets of words and nonwords. Each set consisted of a base word and three items related to it: (1) a PR word with common phonemes in the initial three to seven positions ( $M=4.5$ shared phonemes), (2) an $L$ derived nonword with a single phoneme change in a late position, and (3) an E derived nonword with a single phoneme change in an early position. All words and nonwords had three or four syllables (with the exception of university and its derived nonwords, $u / \mathbf{k} / i v e r s i t y$ and universi $/ \mathrm{k} / \mathrm{y}$ ). The materials are presented in the Appendix. In most cases, the lower frequency word (Francis \& Kučera, 1982) in each pair was designated as $\mathrm{BW}(M=18.5$ for $\mathrm{BW}$, and $M=33.4$ for PR). Thus, if high-frequency words have an advantage in terms of being activated more readily, this would improve chances for observing L-E effects with this indirect phonetic similarity relation,

The study list had 12 words, $12 \mathrm{E}$ nonwords, and $12 \mathrm{~L}$ nonwords, with half presented a single time and half presented three times. Repeated presentations were separated by a minimum of five intervening items. Six serial-position buffer words were used in the first three and final three positions. A total of 78 words and nonwords were presented during study, with items spoken at a 3 -sec rate. On the recognition test, 48 different words were presented, again spoken at a 3-sec rate. Twelve test words were studied words (S), and 36 test words were distractors: 12 had their $E$ nonwords on the study list, 12 had their L nonwords on the study list, and 12 controls (C) had neither of their derived nonwords presented during study. Specific test words were rotated through the repetition and $S, E, L$, and $\mathrm{C}$ conditions. Order of presentation on both study and test trials was random. Lists were recorded by a female speaker using a Macintosh Performa and SoundEdit waveform editing software.

Procedures. The experiment consisted of a single study trial followed by a recognition test. Stimuli were presented via the MacSound application. ${ }^{1}$ Participants were asked to listen carefully to a recorded list of words and nonwords, and they were told there would be a second task that would be explained later. The response requirements for the recognition memory test were described during the 2-min interval that separated presentation of the final study item and that of the first test word.

Participants. Sixty introductory psychology students were randomly assigned to BW and PR conditions and to one of the list conditions required for balancing materials across S, E, L, and C, and the one- and three-repetition conditions. The original plan called for 64 participants so that specific items would be equally represented across conditions. However, data from 4 participants were not included in the analyses. Two students assigned to Group BW were inadvertently given incorrect study and test lists, and this was not discovered until after the experiment had been completed. In order to maintain an equal number of participants across conditions, 2 students in Group PR with list conditions matching those for the disqualified BW participants were selected at random and excluded from the data analyses. All participants indicated that En- 


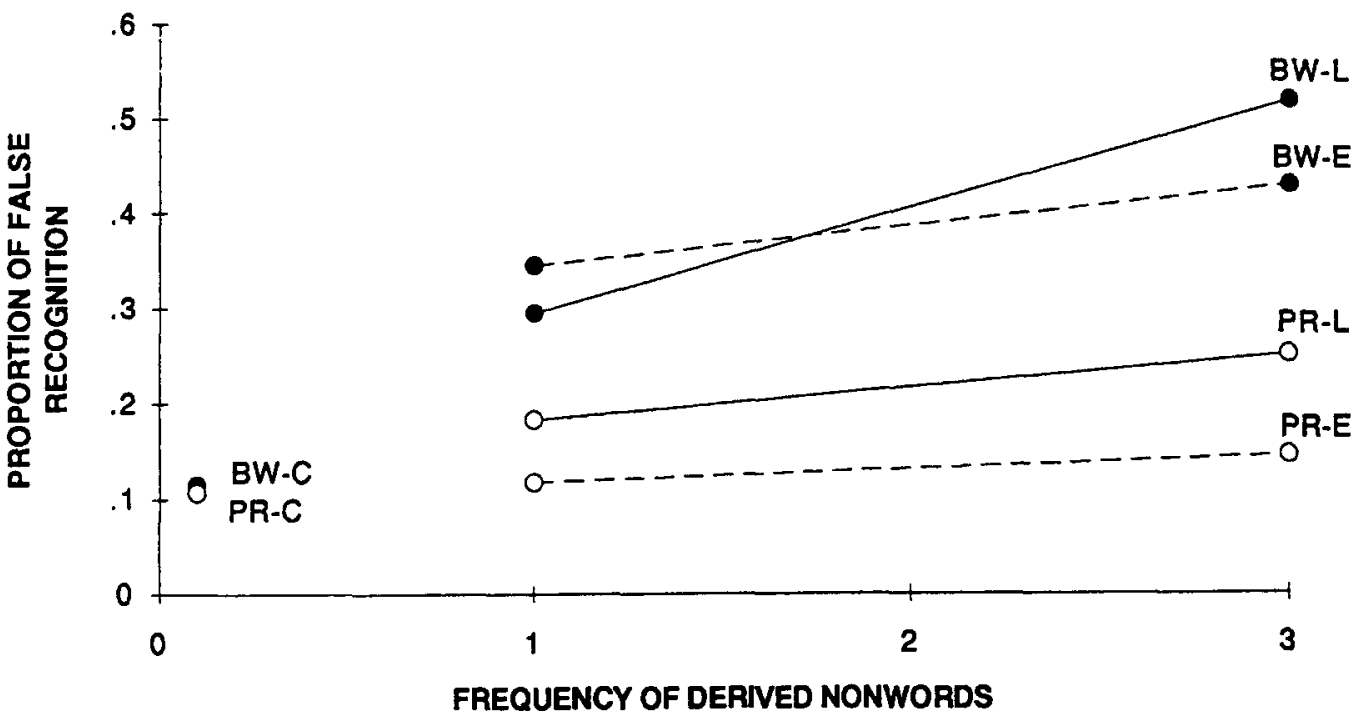

Figure 1. Proportion of false recognitions of base words $(\mathrm{BW})$ and words phonetically related to base words (PR) (corresponding derived nonwords did not appear on the study list for $\mathrm{C}$, had an early phoneme substitution for $E$, and had a late phoneme substitution for $\mathbf{L}$ ).

glish was their first language and that they did not suffer from any known hearing deficits.

\section{Results and Discussion}

Analyses were done with participants and items as random factors. The item analyses are noted only when significance levels differ from the analyses across participants. Three study lists were presented to 8 participants in each group, and one study list was presented to 6 participants in each group; thus analyses of variance (ANOVAs) across items were calculated on transformed error proportions (arcsin transformations; see Winer, Brown, \& Michels, 1991). For these and all subsequent analyses, $\alpha=.05$ was used for statistical significance. Responses of "old" to studied words (S) were correct, and responses of "old" to distractors $(\mathrm{E}, \mathrm{L}$, and $\mathrm{C}$ ) were false recognitions.

The implicit activation theory does not offer any special predictions regarding correct recognition of words that were actually presented on the study list. The only significant contrast in the ANOVA of correct old responses resulted from the higher number correct to words presented three times during study $(M=5.42)$ than to those presented once $(M=4.06)\left[F(1,58)=49.25, M S_{\mathrm{e}}=1.11\right]$.

The data of primary interest involved false recognition as a function of study presentations of derived nonwords. In the $2 \times 2 \times 3$ ANOVA, all main effects were significant. These results are apparent in Figure 1. Group BW made more false recognitions to distractors than did Group PR $\left[F(1,58)=34.02, M S_{\mathrm{e}}=2.17\right]$; there were more errors following three study presentations of derived nonwords than there were following one presentation $\left[F(1,58)=10.03, M S_{\mathrm{e}}=1.48\right]$; and false recognition var- ied as a function of $\mathrm{E}, \mathrm{L}$, and $\mathrm{C}$ conditions $[F(2,116)=$ 63.46, $\left.M S_{\mathrm{e}}=0.74\right]$.

It is important to note from Figure 1 that there were more false recognitions following $L$ than following $E$ derived nonwords on the study list, with the exception of an unexpected reversal in Group BW with one study presentation of derived nonwords. Although minimal prerecognition processing effects may be expected when critical derived nonwords are presented only a single time during study, other experiments varying study list repetitions have not shown a reversal of the $\mathrm{E}-\mathrm{L}$ effect in this condition (Wallace, Stewart, et al., 1995). In addition to the significant main effects, an interaction was present; the differences among $\mathrm{E}, \mathrm{L}$, and $\mathrm{C}$ conditions were not the same for $\mathrm{BW}$ and $\mathrm{PR}$ groups $\left[F(2,116)=23.80, M S_{\mathrm{e}}=0.74\right]$. The interaction between repetitions and $\mathrm{E}, \mathrm{L}$, and $\mathrm{C}$ conditions was significant in the ANOVA across participants $\left[F(2,116)=5.33, M S_{\mathrm{e}}=1.04\right]$, but not for the ANOVA across items. This interaction resulted from the fact that repetition was meaningless for $\mathrm{C}$; and the $\mathrm{C} 1$ and $\mathrm{C} 3$ words were comparable in number of false recognitions.

Specific comparisons of primary theoretical interest involved the contrast between $\mathrm{E}$ and $\mathrm{L}$ conditions. Consistent with previous experiments using this paradigm, there were significantly more false recognitions to $\mathrm{L}$ than to $\mathrm{E}$ test words $\left[F(1,58)=5.90, M S_{\mathrm{e}}=1.02\right] .^{2}$ The interaction contrast involving $\mathrm{E}$ and $\mathrm{L}$ conditions for $\mathrm{BW}$ and $\mathrm{PR}$ groups was not significant, indicating that the $\mathrm{E}-\mathrm{L}$ effect was similar for both groups. Finally, both $\mathrm{E}$ and $\mathrm{L}$ conditions were compared with $\mathrm{C}$ separately for Group $\mathrm{BW}$ and for Group PR. When base words (Group BW) were tested, there were more false recognitions to $\mathrm{E}$ than to $\mathrm{C}$ test words $\left[F(1,29)=103.27, M S_{\mathrm{e}}=1.55\right]$, and there were 
more false recognitions to $L$ than to $C$ test words $[F(1,29)=$ $\left.216.18, M S_{\mathrm{e}}=0.85\right]$. When words phonetically related to base words were tested (Group PR), there were more false recognitions to $\mathrm{L}$ than to $\mathrm{C}$ test words $[F(1,29)=$ $\left.23.81, M S_{\mathrm{e}}=1.12\right]$. The difference in false recognitions to $\mathrm{E}$ and $\mathrm{C}$ test words was not significant. Study trial presentations of either $/ \mathrm{d} /$ ransparent or transparen $/ \mathrm{d} / \mathrm{in}$ creased false recognitions above the control rate to transparent for Group BW. The corresponding test word for Group PR was transportation, and the statistical analyses indicated that only transparen/d/ (the L derived nonword) was effective in increasing false recognitions.

The effectiveness of derived nonwords in activating PR test words may be underestimated in this experiment. Nonwords were derived from base words, and the early portions of some BW and PR test words differed in stress patterns and vowel sounds. Such differences resulted in earlier discrepancies in phonetic overlap between L derived nonwords and PR test words than was assumed on the basis of position of the first letter change. Fifteen of the $48 \mathrm{BW}-\mathrm{PR}$ test word sets had vowel or stress variations that occurred before the late letter change position. It should be noted that this problem resulted in a more conservative test for the PR group. However, vowels are more mutable than consonants (van Ooijen, 1996), and it is not clear whether stress plays an important role in lexical activation of polysyllabic English words (Cutler, Dahan, \& van Donselaar, 1997). In the Appendix, the 15 PR words with altered stress and vowel sounds from their derived nonwords are followed by an asterisk. For this subset of test words, the proportion of false recognitions for $E$ was .08 (it was .13 for the entire set), for $L$ it was .20 (.22), and for $C$ it was .11, identical to the value for all $48 \mathrm{PR}$ words.

The most notable result was that the difference between $\mathrm{E}$ and $\mathrm{L}$ nonwords in producing false recognition was extended to phonetically related words, each matched to a specific base word through the initial three to seven phonemes. One implication is that multiple word candidates are activated as a spoken stimulus unfolds over time (Grosjean, 1980; Tyler, 1984; Zwitserlood, 1989); that is, transparen/d/activates both transparent and transportation as the listener hears /træns/. This extension to PR test words was particularly important for the interpretation that attributes the $\mathrm{E}-\mathrm{L}$ difference to processing activities that operate during the perception of spoken stimuli. If words are accessed in spoken-word recognition through initial phonemes (e.g., Marslen-Wilson, 1987; Taft, 1986), then both BW and PR test words are more likely to be activated during prerecognition processing of $L$ as opposed to $E$ derived nonwords. Nonwords derived from $\mathrm{BW}$ test words should not be effective retrieval cues for activating PR test words during postrecognition processing that occurs during study. ${ }^{3}$

\section{EXPERIMENT 2}

Experiment 2 was designed to test an assumption about prerecognition processing considered responsible for differences in false recognition produced by $\mathrm{E}$ and $\mathrm{L}$ nonwords. It was assumed that base words and words sharing initial phonemes with them would be more highly activated as potential solutions during prerecognition processing of $\mathrm{L}$, as opposed to $\mathrm{E}$, derived nonwords. Implicit activation is assumed to produce familiarity increments, and distractors on a recognition memory test that seem familiar are more likely to be confused with words that were actually presented during study. The claim is not that false recognitions reflect actual remembered episodes of word presentation, but rather that they result from general feelings of familiarity.

A number of investigators have obtained judgments subsequent to recognition decisions indicating whether "old" responses were based on remembering (R) study episodes or whether they were based on knowing $(K)$ that test words were presented during study even though the exact episodes of presentation were not remembered (e.g., Gardiner \& Java, 1990; Rajaram, 1993). Regardless of whether $\mathrm{R}-\mathrm{K}$ procedures actually separate memory reports into those based on remembering and those based on knowing, or whether they just reflect strength differences and the setting of different decision criteria (see Hirshman \& Master, 1997; Inoue \& Bellezza, 1998), it is clear that in contrast to correct "old" judgments, false recognitions to new test words should be accompanied by more K judgments. Dewhurst and Hitch (1997) reported that false-recognition differences between $E$ and L test words appeared only for the subset of errors that were accompanied by $\mathrm{K}$ judgments.

\section{Method}

The principal addition for Experiment 2 was the requirement for participants to give $\mathrm{R}$ or $\mathrm{K}$ judgments for each recognized word. If recognition was based on a conscious recollection of the word being spoken during study, participants were instructed to give an $\mathrm{R}$ judgment. If recognition was not based on conscious recollection, but rather on some other basis for knowing that the test word was on the study list, participants were instructed to give a $\mathrm{K}$ judgment. Precise instructions and examples for $R$ and $K$ judgments were adapted from Rajaram (1993). Because of additional time requirements for $\mathbf{R}-\mathbf{K}$ judgments, the recognition memory test was self-paced, but most judgments were completed within $5 \mathrm{sec}$. In all other respects, the materials and procedures for Experiment 2 were similar to those of Experiment 1 . The participants were 64 introductory psychology students who met normal-hearing and English-as-a-first-language restrictions. Thirty-two participants were randomly assigned to BW and PR groups. The same 48 word sets from Experiment 1 were used in this experiment. Each critical word and nonword was presented three times during study. Serial-position buffer words appeared in the initial three and final three positions of the study list.

\section{Results and Discussion}

Correct old responses. The mean number of "old" responses to studied words was 9.60 for Group BW and 8.66 for Group PR. Unlike in Experiment 1, the difference in number of correct responses between groups was significant $\left[F(1,62)=4.13, M S_{\mathrm{e}}=3.40\right]$. Word frequency was lower for $\mathrm{BW}$ than for $\mathrm{PR}$, but interpreting this result as the usual word frequency effect (e.g., Glanzer \& Bowles, 1976; Gregg, 1976; Wallace, Sawyer, \& Robert- 


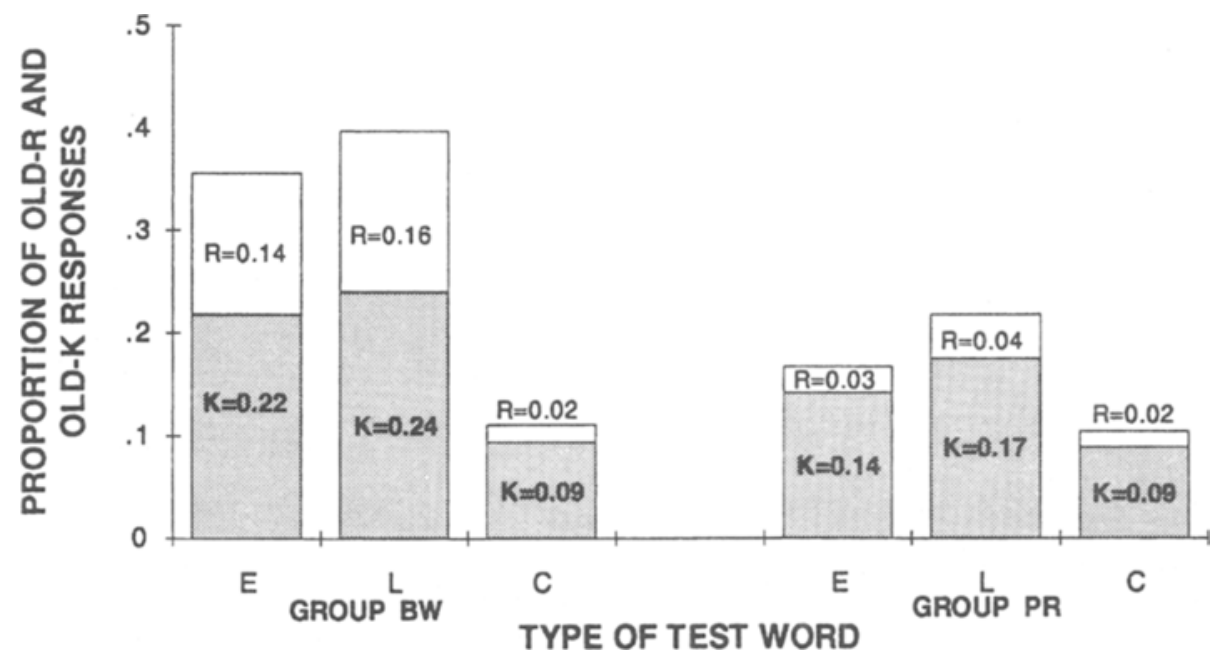

\begin{abstract}
Figure 2. Proportion of "remember" (R) and "know" (K) false recognitions of base words (BW) and words phonetically related to base words (PR). (Corresponding derived nonwords did not appear on the study list for $\mathrm{C}$, had an early phoneme substitution for $\mathrm{E}$, and had a late phoneme substitution for $L$.)
\end{abstract}

son, 1978) is difficult in view of the results from Experiment 1 . However, presence or absence of a word frequency effect on correct recognition is not critical for an evaluation of the primary research question; is recognition memory influenced by implicit word activation during prerecognition processing?

False recognitions. The false-recognition summary data and information on $\mathrm{R}$ and $\mathrm{K}$ judgments are presented in Figure 2. Statistical analyses of false recognition produced results similar to those from Experiment 1 . The two main effects and the interaction were significant. More false recognitions occurred for Group BW than for Group PR $\left[F(1,62)=21.17, M S_{\mathrm{e}}=5.10\right]$. False recognition varied across $\mathrm{E}, \mathrm{L}$, and $\mathrm{C}$ conditions $[F(2,124)=$ $\left.53.94, M S_{\mathrm{e}}=1.86\right]$. There was little variation between $\mathrm{BW}$ and PR groups in false recognition of $\mathrm{C}$ words, whereas false recognitions for $E$ and $L$ conditions were higher for Group BW than Group PR, resulting in a significant interaction $\left[F(2,124)=12.80, M S_{\mathrm{e}}=1.86\right]$.

In general, the follow-up analyses were also consistent with Experiment 1. The contrast of major theoretical importance again showed that there were more false recognitions to test words following study presentations of $\mathrm{L}$, as opposed to $\mathrm{E}$, nonwords $\left[F(1,62)=4.65, M S_{\mathrm{e}}=\right.$ $2.06]$. However, the $\mathrm{L}-\mathrm{E}$ difference was small, and when the analysis was repeated with items as a random factor, the $F$ ratio was not significant. The $\mathrm{E}-\mathrm{L}$ variable did not interact with groups, indicating that the higher number of false recognitions following study of $L$ as opposed to $E$ nonwords was essentially the same for BW and PR groups. Finally, there were more false recognitions in $\mathrm{E}$ and $\mathrm{L}$ than in $\mathrm{C}$ for both groups: For BW, E versus $\mathrm{C}, F(1,31)=$ $55.67, M S_{\mathrm{e}}=2.48$; and $\mathrm{L}$ versus $\mathrm{C}, F(1,31)=99.27, M S_{\mathrm{e}}=$ 1.87. For PR, E versus C, $F(1,31)=9.96, M S_{\mathrm{e}}=0.90$; and $\mathrm{L}$ versus $\mathrm{C}, F(1,31)=16.71, M S_{\mathrm{e}}=1.81$. Among these more detailed comparisons, the only discrepancy from Experiment 1 involved the E-C comparison for Group PR, which was significant in Experiment 2, but not significant in Experiment 1.

$R$ and $K$ judgments. The $R$ and $K$ judgment data were analyzed in two ways. The first measurement procedure reported follows Dewhurst and Hitch (1997) and simply involves a count of the number of old-R and old-K responses. The second measurement procedure reported follows Mather, Henkel, and Johnson (1997) and scores $\mathrm{R}$ and $\mathrm{K}$ responses conditionalized on number of "old" responses such that $p(\mathrm{R} / \mathrm{old})+p(\mathrm{~K} / \mathrm{old})=1.00$.

For the simple count of old $\mathrm{R}$ and $\mathrm{K}$ responses, there were more old-R responses to studied words for Group BW $(M=5.66)$ than for Group PR $(M=4.50)$. The difference was not significant in the ANOVA across subjects, but it was significant in the ANOVA across items $[F(1,94)=$ $\left.5.38, M S_{\mathrm{e}}=2.65\right]$. The groups did not differ significantly in number of old $-\mathrm{K}$ responses to studied words ( $M=3.94$ for Group BW and $M=4.16$ for Group PR).

For the false-recognition data, there were more old- $\mathrm{R}$ responses for Group BW than for Group PR $[F(1,62)=$ 19.56, $\left.M S_{\mathrm{e}}=2.02\right]$. The number of $\mathrm{R}$ false recognitions also varied across $\mathrm{E}, \mathrm{L}$, and $\mathrm{C}$ conditions $[F(2,124)=$ $\left.26.45, M S_{\mathrm{e}}=0.67\right]$. In addition, the interaction was significant $\left[F(2,124)=13.74, M S_{\mathrm{e}}=0.67\right]$. However, E and $\mathrm{L}$ were not involved in a significant main comparison or interaction contrast. In agreement with Dewhurst and Hitch (1997), E and L conditions did not differ in number of $R$ false recognitions for either $B W$ or PR test words. The number of $\mathrm{R}$ false recognitions in Group $\mathrm{BW}$ was higher for $\mathrm{E}$ than for $\mathrm{C}\left[F(1,31)=29.26, M S_{\mathrm{e}}=\right.$ $1.13]$, and it was higher for $\mathrm{L}$ than for $\mathrm{C}[F(1,31)=49.31$, $M S_{\mathrm{e}}=0.89$ ]. For Group PR, E and C conditions did not differ significantly. However, there were more $\mathrm{R}$ false 
Table 1

Summary of Discriminability $\left(A^{\prime}\right)$ and Bias $\left(B_{\mathrm{p}}^{\prime \prime}\right)$ Measures for Remember $(R)$ and Know $(K+R)$ Judgments for $E, L$, and $C$ Distractors

\begin{tabular}{|c|c|c|c|c|c|c|c|c|}
\hline \multirow[b]{2}{*}{ Distractors } & \multicolumn{4}{|c|}{$\mathrm{R}$} & \multicolumn{4}{|c|}{$K+R$} \\
\hline & $p$ (Hits) & $p$ (FAs) & $A^{\prime}$ & $B_{\mathrm{D}}^{\prime \prime}$ & $p$ (Hits) & $p(\mathrm{FAs})$ & $A^{\prime}$ & $B_{\mathrm{D}}^{\prime \prime}$ \\
\hline \multicolumn{9}{|l|}{ Group BW } \\
\hline $\mathrm{E}$ & .47 & .14 & .77 & .74 & .80 & .36 & .81 & -.38 \\
\hline L & .47 & .16 & .76 & .70 & .80 & .40 & .79 & -.45 \\
\hline $\mathrm{C}$ & .47 & .02 & .85 & .96 & .80 & .11 & .91 & .33 \\
\hline \multicolumn{9}{|l|}{ Group PR } \\
\hline E & .38 & .03 & .82 & .97 & .72 & .17 & .86 & .31 \\
\hline $\mathrm{L}$ & .38 & .04 & .82 & .94 & .72 & .22 & .83 & .16 \\
\hline $\mathrm{C}$ & .38 & .02 & .83 & .97 & .72 & .10 & .89 & .56 \\
\hline
\end{tabular}

Note $-p($ Hits $)=$ proportion correct old responses to studied words $p(\mathrm{FAs})=$ proportion of false alarms to new distractors; and $A^{\prime}$ and $B_{\mathrm{D}}^{\prime \prime}$ are measures of sensitivity or discriminability and criterion or bias, respectively (see, e.g., Donaldson, 1996).

recognitions for $\mathrm{L}$ than for $\mathrm{C}\left[F(1,31)=4.30, M S_{\mathrm{e}}=\right.$ 0.44].

For the analyses of false recognitions given $\mathrm{K}$ judgments, only the main effects were significant. Group BW made more $\mathrm{K}$ false recognitions than did Group PR $\left[F(1,62)=4.67, M S_{\mathrm{e}}=3.62\right]$, and the number of $\mathrm{K}$ false recognitions varied among $\mathrm{E}, \mathrm{L}$, and $\mathrm{C}$ conditions $\left[F(2,124)=18.94, M S_{\mathrm{e}}=1.79\right]$. Although there were more old-K responses to $\mathrm{L}$ than to $\mathrm{E}$ test words, these conditions did not differ significantly. Dewhurst and Hitch (1997) found a significant difference between E and L conditions in number of $\mathrm{K}$ false recognitions. Our statistical evidence was not consistent with this result. However, absolute differences between $\mathrm{E}$ and $\mathrm{L}$ test words given $\mathrm{K}$ judgments were small at both laboratories (the proportion of false recognitions given $\mathrm{K}$ judgments was .03 higher for $L$ than for $E$ words in the present experiment, and .06 higher for comparable conditions reported by Dewhurst and Hitch), and there were a number of procedural differences between studies (e.g., Dewhurst and Hitch had a lexical decision study task and a 10-min distractor task after study, and they excluded items if their derived nonwords were incorrectly classified as words during the initial study period).

The second response measure based on conditionalized proportions of "old" responses given $\mathrm{K}$ judgments $[p(\mathrm{~K} / \mathrm{old})]$ revealed that fewer than half of the correct responses to studied words and more than half of the false recognitions were given $\mathrm{K}$ judgments. Also, the pattern of $p(\mathrm{~K} / \mathrm{old})$ responses across $\mathrm{E}, \mathrm{L}$, and $\mathrm{C}$ conditions differed for Groups BW and PR. For E test words, $61 \%$ of false recognitions were given $\mathrm{K}$ judgments for Group $\mathrm{BW}$, and $84 \%$ for Group PR. For $L$ test words, $61 \%$ of false recognitions were given $\mathrm{K}$ judgments for Group $\mathrm{BW}$, and $80 \%$ for Group PR. Both groups were similar in $p(\mathrm{~K} / \mathrm{old})$ for $\mathrm{C}$ test words, with $84 \%$ for Group BW and $85 \%$ for Group PR.

Statistical analysis of $p(\mathrm{~K} / \mathrm{old})$ responses for $\mathrm{E}, \mathrm{L}$, and $\mathrm{C}$ conditions poses difficulties because several participants made zero "old" responses, and the same was true for several items. Only $17 \mathrm{BW}$ and $19 \mathrm{PR}$ participants made one or more false recognition in each of the $E, L$, and $C$ conditions, and only $25 \mathrm{BW}$ and $16 \mathrm{PR}$ test words had at least one false recognition in each of these conditions. The $p(\mathrm{~K} / \mathrm{old})$ values for these restricted sets were similar to the overall values: For the subset of participants, the values for Groups $\mathrm{BW}$ are $\mathrm{E}=.56, \mathrm{~L}=.57$, and $\mathrm{C}=$ .85 , and for Group $\mathrm{PR}, \mathrm{E}=.83, \mathrm{~L}=.79$, and $\mathrm{C}=.82$. For the subset of items, the values for Group $\mathrm{BW}$ are $\mathrm{E}=.64$, $\mathrm{L}=.63$, and $\mathrm{C}=.79$, and for Group PR, $\mathrm{E}=.81, \mathrm{~L}=.88$, and $\mathrm{C}=.89$.

For analysis of these data (following arcsin transformations) with participants as a random factor, the main effects and interaction were significant. The $p(\mathrm{~K} / \mathrm{old})$ responses were higher in Group PR than in Group BW $\left[F(1,34)=5.18, M S_{\mathrm{e}}=1.81\right]$; they varied across $\mathrm{E}, \mathrm{L}$, and $\mathrm{C}$ conditions $\left[F(2,68)=4.35, M S_{\mathrm{e}}=0.61\right]$; and for the interaction, $F(2,68)=3.56, M S_{\mathrm{e}}=0.61$. For Group BW, $p(\mathrm{~K} / \mathrm{old})$ was higher for $\mathrm{C}$ than for $\mathrm{E}[F(1,16)=17.33$, $\left.M S_{\mathrm{e}}=0.40\right]$ and higher for $\mathrm{C}$ than for $\mathrm{L}[F(1,16)=24.87$, $\left.M S_{\mathrm{e}}=0.29\right]$. The $F$ ratios for $\mathrm{E}-\mathrm{C}$ and $\mathrm{L}-\mathrm{C}$ comparisons for Group PR were less than 1.0. The only effect that was significant in the ANOVA with items as a random factor resulted from the higher $p(\mathrm{~K} / \mathrm{old})$ proportions for Group PR than for Group BW $\left[F(1,39)=9.95, M S_{\mathrm{e}}=\right.$ $0.89]$. The results of these analyses suggest that there is a greater tendency for $\mathrm{E}$ and $\mathrm{L}$ words either to be "remembered" from the study trial or to acquire a greater degree of familiarity for Group BW than for Group PR. Either or both of these possibilities could be a by-product of test word activation during postrecognition processing, which is more likely to have occurred for Group BW than for Group PR.

Descriptive measures of sensitivity and bias are relevant for development of a familiarity-based interpretation of the remember/know results. If this distinction reflects the operation of a second decision criterion, then placement of the criterion should be higher for "remember" $(R)$ judgments than for words that participants "know" were on the study list $(R+K$, since an $R$ word also meets the $\mathrm{K}$ criterion). Following procedures set forth by Donaldson $(1992,1996)$, measures of discriminability $\left(A^{\prime}\right)$ and bias $\left(B_{\mathrm{D}}^{\prime \prime}\right)$ were calculated separately for Groups BW and PR, and separately on the basis of false alarms (FA) to each type of distractor word (E, L, and C). The data are summarized in Table 1 . The bias measure $\left(B_{\mathrm{D}}^{\prime \prime}\right)$ reveals that participants set a more conservative criterion for $\mathrm{R}$ than for $\mathrm{K}+\mathrm{R}$ judgments. In addition, both $A^{\prime}$ and $B_{\mathrm{D}}^{\prime \prime}$ for Group BW based on false alarms to either $\mathrm{E}$ or $\mathrm{L}$ distractors did not conform to corresponding values in the other conditions. In terms of a discriminability analysis, the numerical differences suggest that for Group BW there were different "strength" distributions for new E and $\mathrm{L}$ words than for $\mathrm{C}$ words. Also, criteria for responding "old" and "old-remember" were more liberal for these E and $\mathrm{L}$ distractors. If one assumes that there is more than one new item distribution (see Hirshman \& Master, 1997), the present results (which imply that $\mathrm{E}$ and $\mathrm{L}$ test words 
for Group BW acquired additional "strength" during postrecognition processing in comparison with $\mathrm{C}$ words and $E$ and $L$ test words for Group $P R$ ) are compatible with single-process models of the R-K paradigm.

\section{GENERAL DISCUSSION}

There was an increase above the control rate in number of false recognitions to BW and PR test words following study of nonwords derived from base words by changing a single phoneme, and there was additional variation resulting from the location of the changed phoneme. The present experiments added two important pieces of information. First, the data demonstrate that more false recognitions occurred following study of $\mathrm{L}$ as opposed to $\mathrm{E}$ derived nonwords when test words were phonetically related to the base words from which study nonwords were derived (Group PR). The rationale for introducing phonetically related test words was that they were not expected to be activated during postrecognition processing intervals. Differences in false recognitions to $\mathrm{E}$ and $\mathrm{L}$ test words for the PR group should primarily reflect effects of prerecognition processing relatively uncontaminated by postrecognition word activation. $\mathrm{L}$ derived nonwords provided more time for prerecognition activation of PR test words than did $E$ derived nonwords. The present experiments demonstrated a significant difference in false recognitions between $\mathrm{L}$ and $\mathrm{E}$ nonwords.

A second important result involved the distribution of "remember" and "know" judgments of "recognized" words. The proportion of $\mathrm{K}$ judgments accompanying "old" responses was higher for distractors than for studied words. A finding of special interest was that $p(\mathrm{~K} / \mathrm{old})$ judgments were higher for $\mathrm{C}$ than for $\mathrm{E}$ and $\mathrm{L}$ distractors for Group BW. For Group PR, $p(\mathrm{~K} / \mathrm{old})$ judgments were similar for $E, L$, and $C$ distractors. Approximately $45 \%$ of correctly recognized studied words received $\mathrm{K}$ judgments. About $60 \%$ of false recognitions to $\mathrm{E}$ and $\mathrm{L}$ test words for Group BW received $\mathrm{K}$ judgments. The percentage of $\mathrm{K}$ judgments to false recognitions of $\mathrm{C}$ words for both groups, and of $\mathrm{E}$ and $\mathrm{L}$ test words for Group PR, was in excess of $80 \%$. It is reasonable to expect prerecognition processing to be completed quickly and automatically. In contrast, standard procedures for presenting study lists incorporate interitem intervals of $2 \mathrm{sec}$ or longer, sufficient time for deliberate postrecognition strategies to operate.

Postrecognition processing may result in self-generated episodes of word occurrence, whereas prerecognition word activation imparts only general increments of familiarity for activated words. A new word presented on a recognition memory test may elicit a false recognition because it seems familiar owing to prerecognition and postrecognition activation, and a new word activated during postrecognition processing may be remembered as having occurred during the study period. In the latter case, false recognition is due to confusion about details of a remembered study list event: An implicit self-generated occurrence is misremembered as a study presentation. It should be noted that $\mathrm{R}-\mathrm{K}$ data are not informative about whether R judgments are based on a "recovered" experience and $\mathrm{K}$ judgments are restricted to general feelings of familiarity; or whether familiarity provides a basis for both types of judgments (single-process model) with $\mathbf{R}$ used when the underlying feelings of familiarity are "stronger" and above a second, higher criterion. Postrecognition activation of $E$ and $L$ test words for Group BW would lead to a higher proportion of $R$ judgments fer these words in comparison with $\mathrm{C}$ words and all distractors for Group PR, regardless of whether a recovered memory episode or stronger feelings of familiarity provide the basis for R judgments.

Do data from the present experiments have relevance for an explanation of the false-recognition effects of derived $\mathrm{E}$ and $\mathrm{L}$ nonwords in terms of word activation during prerecognition processing? In a limited way, we believe that they do. Although differences in false recognition to distractors following $L$ and $E$ derived nonwords were small, they were present in both experiments. The $\mathrm{L}-\mathrm{E}$ effects were present when the critical distractors tested were the base words from which the nonwords were derived, and they were present when the critical distractors tested were words phonetically related to the base words. When $\mathrm{R}$ and $\mathrm{K}$ judgments were required for each "old" response, there was a greater proportion of "old-R" responses to studied words than to $\mathrm{E}, \mathrm{L}$, and $\mathrm{C}$ distractors. There was a real study episode for each $\mathrm{S}$ word, but none for $\mathrm{E}, \mathrm{L}$, and C words (and, of course, there should be stronger feelings of familiarity for words actually presented during study than for distractors). A larger proportion of $E$ and L words were "remembered" for Group BW (about $40 \%$ ) than for Group PR (about 20\%), a result consistent with the description that test words were more likely to be activated during postrecognition processing for Group BW than for Group PR.

\section{REFERENCES}

BARD, E. G. (1990). Competition, lateral inhibition, and frequency: Comments on the chapters of Frauenfelder and Peters, Marslen-Wilson, and others. In G. T. M. Altmann (Ed.), Cognitive models of speech processing: Psycholinguistic and computational perspectives (pp. 185 210). Cambridge, MA: MIT Press.

Cutler, A., Dahan, D., \& van Donselaar, W. (1997). Prosody in the comprehension of spoken language. Language \& Speech, 40, 141 201.

DEwhurst, S. A., \& Hitch, G. J. (1997). Illusions of familiarity caused by cohort activation. Psychonomic Bulletin \& Review, 4, 566-57I.

DoNALDSON, W. (1992). Measuring recognition memory. Journal of Experimental Psychology: General, 121, 275-277.

DONALDSON, W. (1996). The role of decision processes in remembering and knowing. Memory \& Cognition, 24, 523-533.

FraNCIS, W. N., \& KUČERA, H. (1982). Frequency analysis of English usage: Lexicon and grammar. Boston: Houghton-Mifflin.

GARDINER, J. M., \& JAVA, R. I. (1990). Recollective experience in word and nonword recognition. Memory \& Cognition, 18, 23-30.

Glanzer, M., \& Bowles, N. (1976). Analysis of the word-frequency 
effect in recognition memory. Journal of Experimental Psychology: Human Learning \& Memory, 2, 21-31.

GreGG, V. H. (1976). Word frequency, recognition, and recall. In J. Brown (Ed.), Recall and recognition (pp. 183-216). New York: Wiley.

Grosjean, F. (1980). Spoken word recognition processes and the gating paradigm. Perception \& Psychophysics, 28, 267-283.

HiRshman, E., \& MASTER, S. (1997). Modeling the conscious correlates of recognition memory: Reflections on the remember-know paradigm. Memory \& Cognition, 25, 345-351.

INOUE, C., \& BellezZA, F. S. (1998). The detection model of recognition using know and remember judgments. Memory \& Cognition, 26 , 299-308.

MARSLEN-WiLSON, W. D. (1987). Functional parallelism in spoken word recognition. Cognition, 25, 71-102.

Mather, M., Henkel, L. A., \& Johnson, M. K. (1997). Evaluating characteristics of false memories: Remember/know judgments and memory characteristics questionnaire compared. Memory \& Cognition, 25, 826-837.

MCClelland, J. L., \& Elman, J. L. (1986). The TRACE model of speech perception. Psychological Review, 76, 165-178.

NELSON, D. L., \& DAVIS, M. J. (1972). Transfer and false recognitions based on phonetic identities of words. Journal of Experimental Psychology, 92, 347-353.

NorrIS, D. (1994). Shortlist: A connectionist model of continuous speech recognition. Cognition, 52, 189-234.

Postman, L., \& KePpel, G. (EDS.) (1970). Norms of word association. New York: Academic Press.

Rajaram, S. (1993). Remembering and knowing: Two means of access to the personal past. Memory \& Cognition, 21, 89-102.

RoEdiger, H. L., III, \& MCDERMOTT, K. B. (1995). Creating false memories: Remembering words not presented in lists. Journal of Experimental Psychology: Learning, Memory, \& Cognition, 21, 803-814.

Sommers, M. S., \& LEWIS, B. P. (1999). Who really lives next door: Creating false memories with phonological neighbors. Journal of Memory \& Language, 40, 83-108.

TAFT, M. (1986). Lexical access codes in visual and auditory word recognition. Language \& Cognitive Processes, 1, 297-308.

TYLER, L. K. (1984). The structure of the initial cohort: Evidence from gating. Perception \& Psychophysics, 36, 417-427.

UNDERWOOD, B. J. (1965). False recognition produced by implicit verbal responses. Journal of Experimental Psychology, 70, 122-129.

UNDERWOOD, B. J. (1983). Attributes of memory. Glenview, IL: Scott, Foresman.

VAN OOIJEN, B. (1996). Vowel mutability and lexical selection in English: Evidence from a word reconstruction task. Memory \& Cognition, 24, 573-583.

VROOMEN, J., \& DE GELDER, B. (1997). Activation of embedded words in spoken word recognition. Journal of Experimental Psychology: Learning, Memory, \& Cognition, 23, 710-720.

WALLACE, W. P. (1968). Incidental learning: The influence of associative similarity and formal similarity in producing false recognition. Journal of Verbal Learning \& Verbal Behavior, 7, 50-54

Wallace, W. P., SaWyer, T. J., \& RoberTson, L. C. (1978). Distrac- tors in recall, distractor-free recognition, and the word-frequency effect. American Journal of Psychology, 91, 295-304.

Wallace, W. P., Stewart, M. T., \& Malone, C. P. (1995). Recognition memory errors produced by implicit activation of word candidates during the processing of spoken words. Journal of Memory \& Language, 34, 417-439.

Wallace, W. P., Stewart, M. T., Shaffer, T. R., \& Wilson, J. A (1998). Are false recognitions influenced by pre-recognition processing? Journal of Experimental Psychology: Learning, Memory, \& Cognition, 24, 299-315.

Wallace, W. P., Stewart, M. T., Sherman, H. L., \& Mellor, M. D. (1995). False positives in recognition memory produced by cohort activation. Cognition, 55, 85-113.

WINER, B. J., BROWN, D. R., \& Michels, K. M. (1991). Statistical principles in experimental design. New York: McGraw-Hill.

ZwITSERLOOD, P. (1989). The locus of the effects of sentential-semantic context in spoken-word processing. Cognition, 32, 25-64.

\section{NOTES}

1. MacSound is free software from Yale University.

2. This experiment was repeated with 32 participants per group, and with all critical study items presented three times ( 10 exemplars per $S$ $\mathrm{E}, \mathrm{L}$, and $\mathrm{C}$ conditions). The statistical results were consistent with the experiment reported here. The correct responses to studied words did not differ between groups. The number of false recognitions was higher for Group BW $(M=2.93)$ than for Group PR $(M=1.85)[F(1,62)=$ $\left.11.09, M S_{\mathrm{c}}=4.98\right]$. There was a significant difference in false alarms among the $\mathrm{L}(M=3.12), \mathrm{E}(M=2.75)$, and $\mathrm{C}(M=1.30)$ conditions $\left[F(2,124)=28.28, M S_{\mathrm{e}}=2.11\right]$. The interaction was also significant $\left[F=(2,124)=10.55, M S_{\mathrm{e}}=2.11\right]$, largely because the number of false recognitions to $\mathrm{C}$ words was comparable for $\mathrm{BW}$ and $\mathrm{PR}$ groups. The contrast of primary interest comparing the number of false recognitions following $L$ and $E$ derived nonwords was significant $[F(1,62)=5.42$, $\left.M S_{\mathrm{e}}=0.83\right]$.

3. Word association data are available for many of the PR words used in this experiment (Wallace, Stewart, et al., 1995). The corresponding base words were given as associative responses to PR stimuli and their respective derived nonwords less than $1 \%$ of the time. Although the concern in this experiment is actually with base words and their derived nonwords as stimuli potentially activating corresponding phonetically related words, the data when PR words were stimuli suggest that there may have been little associative mixing across these phonemically overlapping materials. After completion of this experiment, 22 volunteers (10 graduate students, 9 undergraduate students, and 3 classified employees) were given random subsets of 16 base words or $16 \mathrm{~L}$ derived nonwords used in this experiment. Fewer than $2 \%$ of these stimuli elicited their corresponding PR words. Out of 352 response opportunities (22 participants $\times 16$ responses), there were 7 occurrences of a $P R$ word as a word association response (I PR response to a $B W$ stimulus word and 6 to $\mathrm{L}$ derived nonwords). Given the word association data, it does not appear that postrecognition processing of derived nonwords or activated base words involved explicit activation of the PR words used in these experiments.

\section{APPENDIX}

BW-PR Test Words and Replacement Phonemes

\begin{tabular}{lcc}
\hline $\begin{array}{c}\text { Base } \\
\text { Word (BW) }\end{array}$ & $\begin{array}{c}\text { Phonetically Related } \\
\text { Word (PR) }\end{array}$ & $\begin{array}{c}\text { Replacement } \\
\text { Phoneme }\end{array}$ \\
\hline aggravate & agriculture & $/ \mathbf{l} /$ \\
apprehend & appreciate* & $/ \mathbf{r} /$ \\
artifice & artistic* & $/ \mathbf{n} /$ \\
avocado & avocation & $/ \mathbf{r} /$ \\
barracuda & barricade & $/ \mathbf{p} /$ \\
capitulate & capital* & $/ \mathbf{l} /$ \\
catapult & catalog & $/ \mathbf{m} /$
\end{tabular}


APPENDIX (Continued)

\begin{tabular}{|c|c|c|}
\hline $\begin{array}{c}\text { Base } \\
\text { Word (BW) }\end{array}$ & $\begin{array}{c}\text { Phonetically Related } \\
\text { Word (PR) }\end{array}$ & $\begin{array}{c}\text { Replacement } \\
\text { Phoneme }\end{array}$ \\
\hline circumstance & circular & $/ 1 /$ \\
\hline compassionate & comparison & $/ \mathfrak{f} /$ \\
\hline confirmation & confidential & $/ \mathbf{r} /$ \\
\hline culminate & cultivate & $/ \mathbf{p} /$ \\
\hline delivery & deliberate & $/ \mathbf{k} /$ \\
\hline discretion & discrepancy & $/ \mathrm{s} /$ \\
\hline dominoes & domineer & $/ \mathrm{d} /$ \\
\hline enterprise & entertain & $/ \mathrm{k} /$ \\
\hline fertility & fertilizer* & $/ \mathbf{p} /$ \\
\hline generous & generation* & $/ \mathbf{t} /$ \\
\hline happily & happening & $/ \mathbf{t} /$ \\
\hline histogram & historic* & $/ \mathbf{f} /$ \\
\hline horrifify & horizontal & $/ \mathbf{k} /$ \\
\hline hospitable & hospital* & $/ \mathrm{d} /$ \\
\hline impervious & impersonate & $/ \int /$ \\
\hline janitor & January & $/ \mathrm{s} /$ \\
\hline manufacture & manuscript & $/ \mathbf{f} /$ \\
\hline meditate & medicine & $/ \mathbf{p} /$ \\
\hline melody & melancholy & $/ \mathbf{k} /$ \\
\hline ministry & minimize & $/ 9 /$ \\
\hline negligee & negative & $/ \mathbf{s} /$ \\
\hline oppera & operation* & $/ \mathbf{u} /$ \\
\hline paradox & paradise & $/ \mathbf{n} /$ \\
\hline patriarch & patriotic & $/ \mathrm{s} /$ \\
\hline penicillin & peninsula* & $/ p /$ \\
\hline persimmon & persistent & $/ \mathbf{t} /$ \\
\hline pollinate & politician & $/ \mathrm{s} /$ \\
\hline prospectus & prosperity & $/ g /$ \\
\hline regiment & register & $/ \mathrm{k} /$ \\
\hline restoration & restaurant & $/ \mathrm{f} /$ \\
\hline secular & security* & $/ \mathrm{v} /$ \\
\hline serial & seriously & $/ \mathrm{d} /$ \\
\hline signature & significance* & $/ \mathrm{b} /$ \\
\hline solidify & solitude* & $/ \mathrm{m} /$ \\
\hline symphony & sympathetic* & $/ \mathrm{s} /$ \\
\hline television & telegram & $/ \mathrm{p} /$ \\
\hline terrible & terrify & $/ \mathrm{k} /$ \\
\hline transparent & transportation & $/ \mathrm{d} /$ \\
\hline university & universal & $/ \mathrm{k} /$ \\
\hline violin & violent* & $/ \mathrm{s} /$ \\
\hline vitamin & vitality* & $/ p /$ \\
\hline
\end{tabular}

Note-Derived nonwords were created by substituting replacement phonemes for underlined phonemes in BW test words (asterisks identify BW-PR pairs differing in vowel sounds or stressed syllable).

(Manuscript received July 1, 1998;

revision accepted for publication March 24, 1999.) 